\title{
Diminutivos:
}

\section{uma análise comparativa entre o português e o inglês}

\author{
Diminutives: \\ A comparative analysis between Portuguese and English
}

\author{
Rafael Martins Rocha* \\ Helena da Silva Guerra Vicente**
}

Resumo: Diminutivos, sejam eles expressos pela forma sintética ou analítica, constituem um fenômeno comum às línguas do mundo. Em se tratando das formações morfológicas, porém, as propriedades dos afixos avaliativos podem variar a depender das particularidades de cada língua. Este artigo analisa comparativamente a expressão do diminutivo sintético no português e no inglês. Considera-se, portanto, que ambas as línguas dispõem de sufixos de diminutivo, embora seja inquestionável a maior produtividade de construções morfológicas no português que no inglês. A investigação se concentra nos sufixos predominantemente empregados para a formação de diminutivos: inho/-zinho e -ie/y, respectivamente. Uma das principais questões que têm motivado debates acerca do tema é a tentativa de classificação da morfologia avaliativa em relação às categorias flexionais e derivacionais. Baseando-se nos diversos estudos linguísticos sobre o fenômeno sob os mais variados enfoques produzidos na literatura, a comparação do diminutivo das duas línguas visa a levantar discussões quanto à natureza desse processo.

Palavras-chave: Diminutivos. Morfologia avaliativa. Flexão/derivação.

\footnotetext{
* Mestrando do Programa de Pós-Graduação em Linguística da Universidade de Brasília. Membro do Laboratório de Estudos Formais da Gramática (LEFOG) da UnB. Contato: rochamartinsrafael@gmail.com.

${ }^{* *}$ Doutora em Linguística pela Universidade de Brasília (2006). Professor Adjunto do Departamento de Linguística, Português e Línguas Clássicas (LIP) da UnB. Contato: helenaguerravicente@gmail.com.
} 
Abstract: Diminutives, expressed by either the synthetic or analytic form, constitute a common phenomenon across the languages of the world. Considering the morphological formations, however, the properties of the evaluative affixes may vary depending on the particularities of each language. This article analyzes comparatively the expression of the synthetic diminutive both in Portuguese and in English. It is assumed, therefore, that both languages possess diminutive suffixes even though it is unquestionable that the productivity of morphological constructions is higher in Portuguese than in English. The investigation is focused on the suffixes predominantly employed in the formation of diminutives: -inho/-zinho and -ie/y, respectively. One of the main issues that have promoted debates about the theme is the attempt of classification of evaluative morphology in relation to the inflectional and derivational categories. Basing on diverse linguistic studies about the phenomenon produced on varied perspectives in the literature, the comparison of the diminutive of the two languages is aimed at generating discussions on the nature of this process.

Keywords: Diminutives. Evaluative morphology. Inflection/derivation.

\section{Introdução}

Conforme atestam os estudos tipológicos, a noção semântica “diminutivo" é universal. Buscando a máxima precisão de expressão, os falantes estão sempre avaliando o objeto referenciado, ora veiculando sua dimensão, ora transmitindo julgamentos pessoais sobre ele. A maneira como essa categoria se manifesta, entretanto, difere-se translinguisticamente, a depender da estrutura morfológica de cada língua.

As formações sintéticas são consideradas prototípicas por excelência. Adota-se tradicionalmente o uso dimensivo do diminutivo prevalente à expressão atitudinal, que, dependendo do contexto, pode assumir um valor apreciativo ou depreciativo. Porém, contrariamente a essa visão, pesquisas linguísticas têm apontado que a forma sintética tende a ser mais subjetiva, ou seja, pode expressar mais acentuadamente o significado conotativo, expressivo do afixo, ao passo que a analítica tem como característica ser mais objetiva ou denotativa. 
Diminutivos morfológicos são bastante produtivos tanto em português como em inglês. O objetivo deste artigo é investigar essas construções nas duas línguas, a fim de identificar semelhanças e disparidades entre elas, principalmente no que diz respeito à natureza dos sufixos -inho (livrinho, bonitinho, pertinho) e -ie/y (beddie, daddy, sweetie), morfemas de diminutivo mais recorrentes no português e no inglês, respectivamente.

Vale ressaltar que não constitui escopo deste trabalho propor diretrizes pedagógicas para o ensino de tais estruturas. Tal abordagem é assunto suficiente para outro artigo. Este artigo está assim organizado: primeiro, tecese uma síntese de propriedades das morfologias flexional e derivacional; a seguir, aborda-se a morfologia avaliativa nas línguas do mundo; depois, uma seção destinada a uma perspectiva diacrônica sobre o fenômeno; nas duas partes seguintes, os diminutivos do português e do inglês são analisados, respectivamente; e, por último, investiga-se o estatuto dos diminutivos em relação às categorias flexionais e derivacionais de forma a relacionar as línguas em questão.

\section{Flexão e Derivação}

Partindo do pressuposto de que forma e significado estão intimamente associados, Bybee (1985) aponta três principais maneiras pelas quais elementos semânticos podem ser combinados a unidades de expressão:

(i) Expressão lexical-quando um item lexical monomorfêmico acumula dois ou mais conteúdos semânticos. Como em kill 'matar' e drop 'derrubar', que concentram em si as noções semânticas de 'morrer + causar' e 'cair + causar', respectivamente;

(ii) Expressão flexional - composição de elementos semânticos de unidades individualizadas para a constituição do vocábulo. Uma categoria flexional deve ser combinável a qualquer base de apropriada categoria sintática e semântica. Pode se materializar, por exemplo, na forma de acréscimo de afixos a uma base, como acontece com o passado regular dos verbos do inglês: walk 'caminhar' $>$ walk-ed 'caminhar-PASSADO';

(iii) Expressão sintática (ou perifrástica) - itens totalmente separáveis e independentes veiculam elementos semânticos completamente 
distintos. A expressão perifrástica come to know 'vir a saber', utilizada no lugar de realize 'perceber' ilustra esse tipo.

Nessa proposta, não há uma divisão estanque entre as categorias. Os diferentes modos de expressão não possuem delineação pontual, mas constituem grandes áreas interseccionais localizadas em um continuum. $\mathrm{Na}$ transição de uma categoria à outra, há também formas híbridas. Tais elementos não podem ser considerados prototípicos de nenhuma classe em particular, mas constituem grupo à parte exatamente por compartilharem características de mais de um tipo de expressão.

A expressão derivacional seria um exemplo de hibridização: situa-se na faixa de transição entre a expressão lexical e a flexional. Possui aplicabilidade restrita e formações ou significados idiossincráticos, aproximando-se daquela, mas, assim como esta, também se caracteriza pela combinação de dois morfemas distintos em uma mesma palavra. Pode-se citar como exemplo o caso em que o conteúdo de uma base é afetado diretamente pela semântica do sufixo anexado às construções agentivas do inglês formadas por -er (em português, -dor). Mais do que mudar o verbo para nome, especifica que este é o agente da atividade descrita pelo evento: play 'jogar' > player 'jogador'.

Assim, na visão de Bybee (1985), a distinção entre flexão e derivação não possui contornos nítidos. Em se tratando de fenômenos gradientes, o que pode haver por parte dos linguistas é a investigação de determinadas categorias em relação aos diferentes tipos de expressão, que por si só constituem áreas interseccionais de um continuиm.

No entanto, pesquisadores não têm medido esforços na tentativa de traçar conceitos que possam delinear e dissociar cada categoria. Se, por um lado, não se nega a dificuldade de propor uma divisão segura entre morfologia flexional e morfologia derivacional, por outro, diversas análises ressaltam o fato de que cada uma constitui um processo distinto de estruturação de palavras.

Para o português brasileiro, Camara Jr. (1970) foi um trabalho pioneiro. De um modo geral, os critérios assumidos pelo autor como definidores se relacionam à motivação de morfemas na sintaxe. Os flexionais são exigidos pela natureza da frase, constituindo a derivatio naturalis nos termos do gramático latino Varrão (116 - 27 a.C.). Em oposição, afixos derivacionais, derivatio voluntaria, são acionados pela vontade do falante e não pela construção sintática. 
Na referência acima citada, tal distinção se desdobra em três princípios fundamentais: regularidade, concordância e opcionalidade. O primeiro postula que os morfemas flexionais são estruturados em paradigmas coesos e excludentes entre si; os derivacionais, por sua vez, são irregulares e assistemáticos no sentido de que podem variar ou até mesmo faltar a vocábulos congêneres. Os dois últimos estão intimamente relacionados. As formas flexionadas expressam um conteúdo gramatical obrigatoriamente requerido por um contexto sintático e, consequentemente, desempenham concordância e não são opcionais. Os vocábulos derivados são caracterizados pela não concordância e, uma vez que apresentam certa liberdade de escolha, também se distinguem pela opcionalidade.

Além desses princípios distintivos já ressaltados em Camara Jr. (1970), constatam-se pelo menos mais três critérios diferenciadores. Stump (2001) os apresenta da seguinte forma: mudança de significado lexical e parte do discurso, regularidade semântica e configuração estrutural.

Apenas a derivação permite mudança de significado e/ou categoria do vocábulo. As expressões que pertencem ao mesmo paradigma flexional compartilham o mesmo significado lexical e partem do discurso, divergindo apenas no comportamento gramatical de cada forma assumida. Como exemplo, por esse critério, Stump considera que a nominalização ag entiva do inglês no par sing > singer é derivacional, ao passo que a pluralização singer $>$ singers constitui um processo flexional.

A flexão é semanticamente mais regular que a derivação. O conteúdo de um morfema flexional é fixo: o -s do presente indicativo da terceira pessoa do singular no inglês quando acrescido a todo e qualquer verbo nesse contexto possuirá o mesmo conteúdo semântico sempre. Com a derivação, o mesmo não ocorre: o sufixo -ize do inglês, por exemplo, não possui um significado preciso, o que explica as diferentes noções semânticas envolvidas nos verbos derivados de sua adição: winterize 'preparar (algo) para o inverno', hospitalize 'colocar (alguém) em um hospital', vaporize '(fazer) tornar vapor'.

O critério de configuração estrutural do vocábulo se vale da máxima de que o léxico lista lexemas derivados, mas não palavras flexionadas. Não há derivação de uma forma flexionada. Uma consequência desse postulado é que em palavras contendo ambos, afixos flexionais e derivacionais, estes estarão bem mais próximos da base que aqueles. Esse critério tem sido usado 
para motivar um princípio de organização gramatical conhecido como Split Morphology Hypothesis, que considera que toda derivação ocorre no léxico à medida que toda flexão regular é pós-sintática.

Desse modo, ainda que não seja possível estabelecer limites precisos entre flexão e derivação, assume-se, neste artigo, a ideia de que cada morfologia se presta a uma função específica. Nesse sentido, adota-se o raciocínio de Stump (2001), que ressalta a distinção "bem delineada", em sua concepção, entre propriedades morfossintáticas e propriedades léxico-semânticas. Estas apenas determinam a maneira como as palavras entram na composição semântica de constituintes complexos; aquelas estão no nível da sentença, ou seja, operações sintáticas, como a concordância, estão em constante atuação. Em linhas gerais, a morfologia flexional é aquela que envolve a constituição de paradigmas; a derivacional é a que produz lexemas novos.

\section{A Morfologia Avaliativa nas Línguas do Mundo}

Para uma compreensão mais abrangente acerca do tema, antes de focar na análise dos diminutivos nas línguas em questão, é necessário considerar o modo pelo qual a categoria grau é expressa translinguisticamente. Grande parte das pesquisas sobre a gradação adota um viés tipológico (BAUER, 1997; KORTVÉLYESSY; STEKAUER; VALERA, 2012; entre outros). O interesse maior dessas investigações é a identificação dos diferentes mecanismos acionados para a expressão de aumentativos e diminutivos bem como os universais compartilhados entre as diferentes famílias linguísticas.

Estudos tipológicos evidenciam que, com base em construções morfológicas, os aumentativos são menos comuns que os diminutivos. De um modo geral, três tipos de formações sintéticas podem ser verificados entre as línguas do mundo segundo Grandi (2011). No primeiro grupo, há a presença de diminutivos e ausência de aumentativos, sendo o alemão, o holandês e o galês alguns de seus representantes. O segundo grupo se caracteriza pela presença de ambos, como o português, o castelhano, o catalão, o italiano, o romeno e o grego. Por último, encontra-se o conjunto de línguas desprovidas tanto de aumentativos como de diminutivos, como o dinamarquês e o sueco, por exemplo. 
De acordo com o referido autor, o inglês está alocado no terceiro grupo, em que são ausentes diminutivos e aumentativos. Em sua análise, os poucos diminutivos que a língua possui são improdutivos. Tal proposição, no entanto, análoga aos estudos tradicionais de Turner (1973) e Wierzbicka (1985), vai de encontro a trabalhos mais recentes como o de Schneider (2003), em que a produtividade desses sufixos no inglês, com destaques às formações em -ie/y (auntie 'tiazinha', tummy 'barriguinha') e -let (flatlet 'apartamentozinho', kinglet 'reizinho'), é claramente comprovada.

De todo modo, a classificação estabelecida por Grandi (2011) implica a constatação do seguinte universal linguístico na expressão da gradação: se uma língua tem mecanismos morfológicos para formar aumentativos, muito provavelmente também dispõe de diminutivos sintéticos. O contrário, entretanto, não é sempre verificável.

São as características estruturais de cada língua, portanto, que determinam os mecanismos pelos quais diminutivo e aumentativo podem ser expressos. Conforme foi apresentado, formas sintéticas podem faltar para algumas línguas. Nesse caso, as formas analíticas constituem a estratégia disponível. Outras podem se valer dos dois processos. O português e o inglês servem como exemplos no que se refere aos diminutivos, com a diferença de que nesta língua há o predomínio de construções analíticas; naquela, de construções morfológicas.

Nas diversas línguas do mundo, os morfemas de diminutivo e aumentativo são responsáveis por diferentes noções semânticas atribuídas a uma base. Os afixos podem indicar tamanho, mas também veicular o efeito emocional do falante a respeito do objeto, podendo significar, positivamente, afetividade, aprovação, apreciação ou, negativamente, menosprezo, desaprovação e depreciação. Além disso, os mesmos afixos de diminutivo e aumentativo podem expressar conteúdos mais distantes tanto da área semântica denotativa como da conotativa, por exemplo, intensificação, polidez, modéstia. Tendo em vista essas diversas possibilidades de significado materializadas morfologicamente por meio dos afixos gradativos, a literatura tem adotado o termo morfologia avaliativa quando não se está em jogo nenhum uso particular do afixo, mas o fenômeno como um todo.

Também têm sido propostos os tipos de categorias que mais comumente servem de base para afixação avaliativa. A seguinte hierarquia é verificada 
translinguisticamente ${ }^{1}$ : em primeiro lugar, substantivos; seguidos de adjetivos; advérbios e verbos. Numerais, pronomes, interjeições e determinantes estão entre as classes menos típicas. Outra tendência observada é que a aplicabilidade de diminutivos a diversas categorias parece ser maior, comparada à marcação de aumentativos.

A morfologia avaliativa constitui um objeto de investigação de grande interesse às pesquisas linguísticas. $\mathrm{O}$ modo como a expressão dessa categoria se dá - a natureza dos processos morfológicos pelos quais é incorporada na gramática das línguas - apresenta determinadas peculiaridades em relação às categorias flexionais e derivacionais. Conforme destaca Bauer (1997), diversas generalizações a respeito das idiossincrasias da morfologia avaliativa foram postuladas na literatura e, dentre elas, os critérios de Scalise (1984) são os mais citados. Segundo Bauer (1997), se por um lado, há um impasse em assumir generalizações à risca, devido ao fato de estas não se sustentarem empiricamente, levando em conta a diversidade de características morfossintáticas que os afixos avaliativos podem apresentar, por outro, determinados padrões de comportamento podem ser tomados como previsíveis.

$\mathrm{O}$ autor aponta dois aspectos regulares que parecem ser possíveis de se observar nas línguas do mundo: a produtividade e a lexicalização. A morfologia avaliativa é extremamente produtiva nas línguas que dispõem de afixos dessa categoria, aproximando-se, assim, da flexão. Entretanto, mais semelhantemente à derivação que à flexão prototípica, construções cujo conteúdo da palavra resultante se distancia da semântica da base para criar novas possibilidades de interpretação são bastante recorrentes.

\section{Diminutivo e Aumentativo na Diacronia}

Embora sejam os diminutivos o foco deste trabalho, incluem-se os aumentativos nesta seção para fins de comparação. Diacronicamente, o processo evolutivo dessas duas categorias aconteceu de maneiras distintas. Os diminutivos surgem por mecanismos de renovação, ao passo que os aumentativos resultam de uma inovação.

${ }^{1}$ Ettinger (1974) e Nieuwenhuis (1985), citados por Bauer (1997). 
Com base em Greenberg (1995), Grandi (2011) sustenta que a gênese de categorias linguísticas depende de dois fatores principais: estabilidade e frequência. $\mathrm{O}$ primeiro conceito está relacionado à grande probabilidade de uma língua, ou uma família inteira, de preservar determinadas características do ancestral do qual se originou. $\mathrm{O}$ segundo diz respeito à possibilidade de uma língua, ou esporadicamente um grupo, instaurar um estado particular.

O latim não possuía o aumentativo prototípico, ou seja, um "sufixo puro" que servisse de mecanismo formal para expressão dessa categoria, mas dispunha de um sufixo derivacional bastante produtivo: -i(o), -(i)onis, terminação (desinência) do genitivo singular da terceira declinação. Na maior parte dos casos em que era empregado, esse sufixo formava substantivos masculinos animados, designando seres humanos com características físicas peculiares ou também hábitos e ações praticados exageradamente. A pejoratividade e a noção de grandeza são os componentes semânticos básicos do sufixo latino. Por exemplo, nasus 'nariz' > naso 'pessoa com nariz grande', edere 'comer' > edonis 'comilão'.

Para o diminutivo, duas tendências são apontadas como possíveis origens semânticas. Uma das hipóteses é a de que o valor hipocorístico tenha sido o principal desencadeador dessa noção conceitual. Outra, a qual os pesquisadores $^{2}$ preferem adotar, diz respeito à designação da relação genealógica pai-filho/adulto-jovem como ponto inicial do processo de diminutivização. Esta última hipótese tem prevalecido sobre a primeira por ser possível verificar no sufixo latino -inus - que resultou nos diminutivos românicos -ino (italiano), -ín (espanhol), -inho (português) - tal valor. Como exemplo: Messalinus - 'nascido de M. Valerius Messala Messalinus'; Agrippina - 'filha de Agrippa'. Infere-se, assim, que foi o sentido "filho/ jovem de X" que precedeu a noção semântica "X pequeno".

Desse modo, Grandi (2011) considera que os diminutivos são o que se poderia chamar de "quasi-universal", nos termos de Greenberg (1995). Esses sufixos têm uma larga difusão nas línguas do mundo, ou seja, possuem alto grau de estabilidade. São atestados, por exemplo, em todas as línguas românicas por terem herdado a categoria semântica "diminutivo" do latim. Os meios

2 Butler (1971), Jurafsky (1996). 
formais para expressão de diminutivo foram apenas atualizados. $\mathrm{O}$ aumentativo, porém, é marcado pela instabilidade. No caso das línguas românicas, nem todas o possuem, como é o caso do francês. Dessa forma, a frequência supera a estabilidade e, por isso, essa categoria foi introduzida pelas línguas neolatinas, com a emergência de sufixos de aumentativo próprios, ausentes no latim.

\section{Diminutivos no Português}

O diminutivo é bastante produtivo no português brasileiro, podendo inho e -zinho se anexarem a praticamente todo tipo de base, exceto artigos:

a) pronomes - euzinho, aquelazinha;

b) substantivos - barzinho, bolinha, cafezinho, detalhezinho, finalzinho, friozinho, menininho/meninozinho, pãozinho, pedacinho, peixinho/ peixezinho, solzinho;

c) adjetivos - cheinho, limpinho, pobrinho/pobrezinho, quentinho;

d) verbos - nas formas nominais: particípio: arrumadinho, escondidinho, torradinho;

gerúndio: chorandinho/chorandozinho, dormindinho/ dormindozinho;

e) advérbios - devagarinho/devagarzinho, direitinho, pertinho.

Observa-se recorrentemente a possibilidade de alternância entre as formas -inho/-zinho no mesmo contexto morfofonológico: devagarinho/ devagarzinho, chorandinho/chorandozinho etc. Vale acrescentar que também pode haver o acúmulo de marcas de diminutivo no mesmo vocábulo. Nesse caso, a sequência linear -inho/-zinho deve ser mantida: menininhozinho (*meninozinhoinho), cachorrinhozinho (*cachorrozinhoinho).

Quanto à distinção -inho/-zinho, a literatura dispõe de propostas diversas. Há análises que os consideram alomorfes; por exemplo, Ferreira (2005), que postula ser a formação 'X-inho' estabelecida no nível da raiz, resultando em substantivos ou adjetivos formados com as vogais temáticas (pedac-o $>$ pedac-inh-o, bol-a > bol-inh-a), ao passo que 'X-zinho' provém de palavras terminadas em consoantes, ditongos ou vogais tônicas (bar $>$ barzinho, pão $>$ pão-zinho, café $>$ cafe-zinho). Mas também há pesquisas que se alinham à de Bisol (2010) e assumem -inho como diminutivo canônico, 
propondo-se, assim, ser a epêntese da consoante $z$, também observada em outros sufixos derivacionais al $\sim$ zal, eiro $\sim$ zeiro etc, ativada por demandas estruturais.

Ambos os sufixos, porém, podem ser precedidos de mudanças morfofonológicas provocadas pela marcação flexional de plural. Por exemplo:

f) $\mathrm{P}[\tilde{\mathfrak{B}} \tilde{\mathrm{w}}] \mathrm{p}[\tilde{\boldsymbol{B}} \tilde{j}] \mathrm{s}>\mathrm{p}[\tilde{\boldsymbol{E}} \mathbf{j}]$ zinhos - mudança do ditongo: $<$ ão $>$ (sing.) $\rightarrow$ $<\tilde{a} \mathrm{e}>(\mathrm{pl}$.)

g) Jorn[aw] $>$ jorn[aj]s $>$ jorn[aj]zinhos - mudança do ditongo: $<$ al $>$ [aw] (sing.) $\rightarrow<$ ai $>$ (pl.)

h) $\mathrm{P}[\mathrm{o}] \mathrm{rco}>\mathrm{p}[\mathrm{o}] \mathrm{rcos}>\mathrm{p}[\mathrm{o}] \mathrm{rquinhos}-$ mudança da qualidade da vogal, de fechada (sing.) a aberta (pl.).

Nos dados listados acima (a-h), -inho/-zinho apenas atribuem um acréscimo semântico à base, ou seja, tais sufixos não alteram as propriedades formais (morfossintáticas) do vocábulo. Por exemplo, em $[\mathrm{eu}]_{\text {pron. }}>$ $[\text { euzinho }]_{\text {pron. }},[\mathrm{casa}]_{\text {subst. }}>[\text { casinha }]_{\text {subst. }}$, [quente $]_{\text {adj. }}>$ [quentinho $_{\text {adj. }}$, $[\text { dormindo }]_{\text {verbo }}>[\text { dormindinho }]_{\text {verbo, }}[\text { perto }]_{\text {adv. }}>[\text { pertinho }]_{\text {adve, }}$, classe e gênero do imput e output se mantêm idênticos. Percebe-se assim que, diferentemente de alguns sufixos derivacionais, tais como -ção: canalizar $r_{\text {[verbo] }}>$ canalização $_{\text {[subst.] }}$ e -eiro: a casa $a_{[\mathrm{fem}]}>$ o caseiro $_{[\mathrm{masc}]}$, -inho e -zinho não carregam informações de categoria e gênero, apenas atribuem o traço avaliativo.

Pode haver, no entanto, casos em que a palavra resultante se desvincula da base para lexicalização de novos conceitos:

i) camisinha - "preservativo"; coxinha - "salgado"; selinho - "beijo"; branquinha - "cachaça"; pedalinho - "meio de transporte aquático"; caipirinha - "tipo de bebida alcoólica".

Evidenciam-se, assim, dois agrupamentos de formações diminutivizadas: um que mantém forte relação com a base, dados (a-h), e outro que a modifica mais acentuadamente, ilustrado em (i). No primeiro caso, o sufixo apenas modifica determinada noção da base, conservando a categoria e o gênero da palavra formada, como: menino > menininho/menininha. O segundo, -inho atribui novas possibilidades de interpretação, além de influenciar mais fortemente as propriedades formais da palavra resultante, isto é, uma nova palavra é derivada: branco $_{\text {[adj. masc.] (cor) }}>$ branquinh $_{\text {[subst. fem.] (cachaça) }}$.

Conforme destaca Armelin (2011), outra distinção considerável é o fato de apenas as construções 'X-inho' composicionais (diminutivos não 
lexicalizados) poderem apresentar interação com as marcas de aumentativo. A essa questão, as formações composicionais se destacam pela rigidez da disposição dos sufixos: os aumentativos precedem os diminutivos obrigatoriamente. Por exemplo:

j) calorãozinho (*calorinhozão), carrãozinho (*carrinhozão), meninãozinho (*menininhozão), bobãozinho (*bobinhozão), chatãozinho (*chatinhozão), arranhãozinho (*arranhinhozão).

$\mathrm{O}$ teor da influência exercida pelos sufixos de diminutivo à base interfere no comportamento dos dados. Diminutivos (e também aumentativos) composicionais podem formar diversas categorias: substantivos, adjetivos, advérbios, gerúndios e particípios. Porém, construções não composicionais (diminutivos lexicalizados) parecem se restringir à formação de substantivos.

Em termos de significação, considerando particularmente as formações composicionais, os sufixos de diminutivo em português podem ser usados em diferentes contextos e, consequentemente, veicular uma gama variada de noções semânticas à base. Embora de um modo geral a gramática tradicional tenha optado por enfatizar quase que exclusivamente o uso dimensivo do grau, dentre os diversos matizes que -inho pode assumir, destacam-se pelo menos três usos, apontados por Rocha (1998):

(1) Subjetivo - envolve a subjetividade do falante (carinho, amor, educação). Para ilustrar, o autor dá o seguinte exemplo: “-Filhinho, vai para a caminha tomar o seu leitinho!";

(2) Valorativo - expressa um julgamento de valor, seja ele positivo ou negativo, sobre um referente. $\mathrm{O}$ contraste de valoração pode ser observado em: “- Este é o timinho do meu coração!”, quando -inho é um sufixo melhorativo, em oposição a "- Este timinho viajou de ônibus!", em que o sufixo é pejorativo;

(3) Diminutivo - denota tamanho reduzido. Por exemplo, “- Ele mora naquela casinha da esquina".

Essa natureza tríplice do sufixo de grau, segundo Rocha, constitui evidência suficiente para propor uma redenominação dos sufixos recorrentemente classificados como diminutivo ou aumentativo. Em consonância ao trabalho de Rosa (1982), o autor considera que "toda formação gradual complexa expressa necessariamente afetividade” (ROCHA, 1998, p. 40). Dessa forma, sufixos de grau deveriam, na verdade, ser chamados de sufixos afetivos. 
Entretanto, o que parece ser negligenciado em tal posicionamento é o fato de o sufixo de grau também poder veicular uma semântica de caráter regular, a de intensificação, em que noções de emotividade/subjetividade, caso presentes, sejam componentes de natureza secundária. Incluem-se aqui adjetivos, advérbios, gerúndios e particípios:

(4) - O balde está cheinho d’água. (= tão cheio quanto poderia estar)

(5) - Eu te devolvo agorinha mesmo! (= neste exato momento)

(6) - Hoje a casa amanheceu limpinha! (= tão limpa quanto poderia estar)

(7) - Eu vou lá correndinho. (= o mais rápido possível).

(8) - Ele deu uma saidinha, mas já volta! (= uma saída mais breve possível)

Nos exemplos que Rocha (1998) fornece, listados em (1-3), -inho é acionado pela vontade do falante, considerando sua expressividade em relação a determinado contexto. Em (2), especificamente, são questões pragmáticas que determinam o valor do julgamento, isto é, o aspecto positivo ou negativo que o sufixo pode apresentar quando possui função valorativa. Timinho, por exemplo, possui conteúdo melhorativo se empregado na situação em que demonstre apreço pelo falante, mas pejorativo se há a intenção de expressar depreciação.

Distintamente, em (4-8), seja qual for a situação de fala, o sufixo se comporta como intensificador. Os dados localizam-se em torno de um sentido fixo: alto grau de intensidade da propriedade ou evento descrito pela base. A sufixação de -inho, nesses casos, está mais próxima de ser o resultado de uma constatação de uma realidade objetiva que a impressão puramente subjetiva do falante sobre um determinado referente.

Observa-se, assim, que o conteúdo produzido pelo sufixo em (1-3) se distingue do acréscimo semântico presente em (4-8). No primeiro caso, -inho veicula uma forte carga atributiva. Seu significado pode ser parafraseado tanto por um adjetivo que possua significado mais denotativo (tamanho: pequeno) ou por um termo que expresse as diversas conotações que o sufixo pode assumir (afetividade: amado, querido; apreço: estimado, favorito; depreciação: repulsivo, desprezível, ruim; entre outros). O segundo, por sua vez, demonstra que, apesar de -inho apresentar certo teor polissêmico no que diz respeito à classe dos nomes, para as demais classes, o sufixo faz a palavra resultante significar 'mais X que a base' invariavelmente. 
Desse modo, propõe-se o seguinte questionamento: a morfologia avaliativa é necessariamente expressiva? Se, por um lado, tradicionalmente apenas um significado de -inho, o denotativo, tem sido privilegiado, por outro, é possível notar que pesquisas linguísticas, em sua maioria (para citar algumas: SANDMANN, 1989; LOURES, 2000; GONÇALVES, 2008), têm adotado um enfoque expressivo-estilístico sobre o tema. A natureza intensificacional dos diminutivos ainda carece de investigações aprofundadas e sistemáticas.

\section{Diminutivos no Inglês}

Diminutivos analíticos, também chamados de modificação sintática, são mais típicos no inglês que os sintéticos. Mesmo as análises que afirmam a inexistência de construções morfológicas na língua consideram as formações analíticas como um tipo possível de diminutivo. Assim como as formas sintéticas revelam as estruturas gerais de línguas eslavas e românicas, as analíticas são características do inglês.

Esse modo de expressar a gradação consiste na estrutura: adjetivo (marcador de diminutivo) + substantivo (base). O adjetivo pertence ao campo semântico da palavra SMALL ('PEQUENO'). Pelo menos os seguintes adjetivos compartilham o mesmo significado e servem de componentes para a forma analítica (denotando inferioridade a um determinado padrão):

a) small - I've known him since he was a small boy;

b) little - It was another of her silly little jokes;

c) tiny - His tiny little puppy is so cute;

d) wee - My wee boy is two;

e) teeny - I'll just have a teeny piece of cake;

f) diminutive - He's a shy diminutive man.

Não há como negar, no entanto, que, no inglês, small e little são os principais adjetivos do campo semântico SMALL. Ambos são formas não marcadas, neutras. A distinção que pode ser feita entre eles é que, em little, implicações emocionais estão presentes; em small, ausentes.

O significado de small é estritamente quantitativo. A objetividade de expressão predomina sobre o valor atitudinal. Via de regra, small qualifica uma propriedade do referente e, implicitamente, estabelece uma comparação. Ora, gramaticalmente, small, e não little, figura em estruturas comparativas e superlativas. 
Ainda há muito a investigar sobre o estatuto dos diminutivos na língua inglesa. Estudos comparativos podem ter muito a revelar, desde que feitas as devidas ressalvas sobre as características estruturais particulares de cada língua em questão. O inglês, particularmente, parece possuir mais natural e predominantemente diminutivos analíticos. Contudo, as formações sintéticas existem, sim, e em escala muito superior ao que se tem considerado tradicionalmente.

Há uma gama enorme de sufixos diminutivos ingleses. É possível fazer um levantamento de pelo menos 86 formativos diferentes desse tipo na língua. A pesquisa quantitativa de Cannon (1987) sustenta que os sufixos de diminutivo estão entre os afixos mais produtivos do inglês. Vale lembrar, porém, que as mudanças históricas a que se submete o inventário dos sufixos gradativos aceleram o processo de obsolescência destes.

Desse modo, assim como o português, o inglês é uma língua que apresenta diminutivos sintéticos. Estes são criados na espontaneidade do momento da fala informal, sem quaisquer limitações à fala infantil. Schneider (2003) aponta 14 sufixos usados atualmente no inglês. O enfoque deste trabalho será nas formações com o sufixo -ie/y.

Muitos autores consideram -ie como o sufixo de diminutivo prototípico da língua inglesa. Cannon (1987) constata estatisticamente que -ie ocupa a $12^{\mathrm{a}}$ posição em termos de produtividade dentre 96 sufixos mais produtivos do inglês. O sufixo possui a variante ortográfica -y. Esta parece ser a escrita preferida no inglês britânico e americano, enquanto aquela é a que mais predomina no inglês escocês e australiano. A forma -ey ocorre com bases terminadas em -e.

Não há consenso entre os linguistas quanto à classificação de -ie/y. As análises variam desde o enfoque ao seu caráter hipocorístico até à rotulação do sufixo como marcador de familiaridade. Schneider (2003) considera que conceituá-lo como qualquer outra coisa diferente do termo diminutivo leva a definições imprecisas. Como sufixo de diminutivo, -ie/y geralmente indica familiaridade entre o falante e o ouvinte, mas também pode expressar apreciação ou depreciação dependendo do contexto (base + situação de fala) em que se encontra.

Diversas categorias podem formar diminutivos em -ie/y: substantivos (pig > piggy), adjetivos (short > shorty), verbos (weep > weepie), advérbios (alright 
$>$ alrightie) e, possivelmente, interjeições (Lordy!). É inegável, porém, que não só substantivos e adjetivos são as classes formativas de diminutivos mais frequentes, como construções vindas de verbos e advérbios são bem raras na língua.

Entre nomes próprios, prenomes são mais frequentes que sobrenomes. Diminutivos podem ser formados com todos os prenomes, masculinos, Billy, Bobby, Freddie, Johnny, e femininos, Annie, Betty, Susie.

Substantivos comuns diminutivizados podem se referir a:

(1) pessoas - auntie, buddy, chappie, daddy, granny, hubby, kiddy, laddie/laddy, mummy, sonny;

(2) animais - birdie, doggie, horsey, kitty, piggy, puppy, sheepy;

(3) objetos - beddie, hanky, housey, lippie, nappies, nightie, panties, potty, sunnies, undies.

O primeiro grupo está associado à relação familiar (daddy, buddy, granny etc.); o segundo se refere a animais domésticos (doggie, horsey, sheepy etc), conferindo-lhes o traço [+ pequeno] e veiculando afetividade entre o falante e o termo referenciado; o último inclui objetos do mundo infantil (beddie, potty etc.) ou do mundo cotidiano, representados por palavras de estrutura complexa (lipstick > lippie, sunglasses $>$ sunnies etc).

Conforme ilustram esses dados, as bases às quais o sufixo se anexa podem ser tanto monossilábicas ( $b a d>$ baddy, bird $>$ birdie etc) como polissilábicas, caso em que são truncadas para a formação do diminutivo (football $>$ footie, husband $>$ bubby etc.). Consoantes pospostas à vogal curta duplicam-se com o acréscimo de -ie/y (dad $>$ daddy). Todos os diminutivos construídos com o sufixo, todavia, são substantivos dissílabos cuja sílaba tônica é a primeira. Também se observa que, se a palavra derivativa estiver no plural, o diminutivo derivado também fica pluralizado (underclothes $>$ undies).

Como regra geral, os diminutivos formados com -ie são substantivos. Isso implica dizer que os diminutivos deadjetivais, geralmente usados na sentença pospostos ao determinador such, mudam a categoria da base. Os dados abaixo ilustram essa situação:

\section{a) ADJETIVOS}

She had a big grin on her face.

The girls all think he's hot.

It's a mean trick to play on someone.

\section{b) SUBSTANTIVOS}

Their new CD is going to be a biggie!

$\rightarrow$ She's such a hottie!

Don't be such a meanie! 
Esses exemplos também podem ser estritamente associados à natureza intensificacional - à qual se chamou atenção na seção anterior - veiculada pelo sufixo de diminutivo em alguns casos. Os diminutivos originados de adjetivos, além de mudar a categoria da base, possuem uma semântica de maximização do conceito desta. Contrariamente ao que se esperaria, essas formações não indicam 'little/small X'. Os diminutivos deadjetivais exprimem intensificação. Os significados de baddie, biggie, hottie, meanie, quickie, shorty, sweetie podem ser parafraseados por 'que é o mais X/o que mais possui X', ou seja, imprime-se o valor superlativo a esses casos.

Pode haver, contudo, a manutenção da categoria da base. São exemplos os diminutivos formados de adjetivos que forem empregados como tais em contexto sintático específico, como em 'Is the quickie divorce just for celebrities?'. Entretanto, esses casos são considerados exceções uma vez que, mesmo que possam ser empregados sem a mudança de classe da base, possuem a contraparte heterocategorial, ou seja, o resultado mais comumente esperado é a alteração da categoria da base, envolvida na formação de substantivos: 'I've got a question for you - it's just a quickie'. O que é interessante notar é que é justamente o fato de substantivos terem sido formados a partir de adjetivos que possibilita a interpretação intensificacional das construções ' $\mathrm{X}$-ie' deadjetivais.

Diminutivos lexicalizados também são possíveis. Nessa situação, o resultado não é a mera soma dos conteúdos do radical e do sufixo, mas a lexicalização da junção de seus significados formando um terceiro conceito.

(5) a) cookie - 'biscoito': My granny, she makes the best cookies in the world!

b) foodie - 'pessoa apaixonada por comida': Trust me, I'm a foodie.

c) leftie - 'esquerdista': Why it's right to be a leftie (manchete de jornal).

d) weepie - 'filme/romance/música emocionante ou sentimental': Take your hankies ${ }^{3}$ with you because this is a weepie.

3 A palavra hankies ('lencinhos') também está no diminutivo (base: handkerchiefs 'lenços'). Contudo, o exemplo visa a destacar apenas o diminutivo lexicalizado, ou seja, weepie. 


\section{Diminutivos no Continuum Flexão/Derivação: comparando o português e o inglês}

Conforme exposto na primeira seção, flexão e derivação não são morfologias totalmente estanques. Existem, no entanto, tentativas de se delinear seus contornos, pois, ao mesmo tempo em que são interseccionais, possuem características próprias que as definem como categorias diferentes. Sendo assim, em não se tratando de conjuntos discretos, deve-se sempre ter em mente que a separação das duas morfologias se dá por uma questão de gradiência, ou seja, os morfemas se comportam mais semelhantemente a uma que à outra em relação a critérios específicos.

Classificar os afixos avaliativos tem se mostrado uma árdua tarefa que emerge polêmica entre os linguistas. A gradação está muitas vezes relacionada à subjetividade do emissor. Ao marcar um vocábulo com morfemas de diminutivo, enfatizando-o ou dimensionando-o, também se expressam os juízos de valor sobre a coisa ou pessoa a que se está referindo. Além disso, embora talvez menos focalizado, o aspecto avaliativo dos afixos pode estar associado a conteúdos menos subjetivos e pragmáticos, vinculando-se mais acentuadamente à objetividade de uma realidade concreta. Por isso, grandes dificuldades surgem na tomada de uma posição radical para considerar o grau como puramente processo flexional ou puramente derivacional. Trata-se de um fenômeno que vai além dos limites do campo da morfologia, tornando-se necessário, assim, analisá-lo sob as perspectivas morfopragmática e morfossemântica.

Esta seção, então, analisa como o fenômeno, tanto no português como no inglês, se comporta em relação aos critérios recorrentemente considerados pela literatura. A relevância sintática talvez seja o mais referenciado deles. Uma característica distintiva da flexão é que esta é requerida pela sintaxe. Considera-se que os afixos gradativos são imotivados pela construção sintática; ou seja, em relação a esse critério, comportam-se derivacionalmente.

O que parece ficar em aberto, contudo, é o alcance da opcionalidade do falante. Até que ponto a escolha de vocábulos afixados é arbitrária? Pragmaticamente, contextos de uso podem favorecer seu acionamento. Staverman (1953), por exemplo, em seu estudo sobre o holandês, mostra que a ocorrência de diminutivum modestum é altamente previsível nos contextos em que o falante procura evitar exagero/ostentação de suas conquistas pessoais. 
Situação de fala que também parece motivar diminutivos no inglês ("Here's a little something for your birthday") e no português ("Hoje eu tenho um carrinho na garagem").

Semanticamente, considerando as formações em que o sufixo é um intensificador, é possível até a identificação da atuação de princípios de natureza mais gramatical, isto é, fatores morfossemânticos envolvidos no acionamento do grau. Ora, os sufixos -inho e -ie/y veiculam um significado regular, que é o de comparação gradual em relação à base. Os pares cheio vs. cheinho/hot vs. a hottie, por exemplo, demonstram que a forma sufixada representa 'mais X do que a base’. Isso significa que não é possível uma mera intercambialidade entre as formas sem que haja alteração semântica significativa.

O que se está questionando aqui são os desdobramentos do critério da obrigatoriedade sintática e não o critério em si. Pode ser que, se associado às demais perspectivas, a não obrigatoriedade sintática venha a revelar muito mais informações sobre o que a "opcionalidade" dos afixos gradativos significa de fato.

Outro critério que revela a natureza derivacional do diminutivo morfológico nas duas línguas em questão é o que diz respeito a seus meios de materialização. A flexão, derivatio naturalis nos termos do gramático latino Varrão, é o único veículo de exteriorização do conteúdo semântico. Diferentemente, a derivação, derivatio voluntaria pode ser parafraseada por meio de outras estratégias ${ }^{4}$. A variedade de formas que existe dentro da própria gradação - forma sintética e forma analítica - ilustra suficientemente as diversas possibilidades de meios de expressão.

Em relação à produtividade, em português -inho se aproxima do eixo flexional. A flexão é mais produtiva que a derivação, uma vez que seu paradigma tende à generalidade. Apesar de Camara Jr. à sua época não ter concordado com o fato de o diminutivo poder ser largamente aplicado aos substantivos portugueses, Piza (2001), por exemplo, constata ser possível acrescentar afixos de grau a praticamente todos os nomes da língua.

Os diminutivos sintéticos do inglês, por sua vez, apresentam características um pouco distintas neste quesito. De um modo geral, são

\footnotetext{
${ }^{4}$ Gonçalves (2008), para caracterizar flexão e derivação, utiliza os termos "morfologia aprisionadora" e "morfologia libertária", respectivamente.
} 
bastante produtivos, mas não são aplicáveis uniformemente entre as categorias. Se, por um lado, praticamente todos os nomes podem ser diminutivizados, construções deadjetivais não são atestadas sistematicamente. Além disso, formações com verbos e advérbios são raríssimas na língua. Desse modo, os diminutivos do inglês estão no âmbito derivacional, tendo por base o critério da produtividade.

A não excludência e recursividade mais uma vez apontam a natureza derivacional do sufixo gradativo do português. Morfemas flexionais não podem coocorrer, tampouco acumularem-se no mesmo vocábulo. As duas possibilidades, todavia, podem ser observadas empiricamente com -inho: a presença de duas marcas de diminutivo, como em menininhoz̧inho, vidinhaz̧inha e a combinação aumentativo-diminutivo, arranhãoz̧inho/beijãożinho.

No inglês, é difícil julgar o comportamento do sufixo -ie em relação a esse critério, uma vez que não há outro sufixo que seja semelhante na forma e esteja associado a ele do mesmo modo que os sufixos de diminutivo do português -inho e -zinho. Além disso, também não seria possível identificar se a língua permite o acúmulo de morfemas avaliativos, já que não dispõe de aumentativos.

Uma das principais diferenças entre flexão e derivação apontada pela literatura é a possibilidade de apenas esta poder mudar a classe a que pertence o vocábulo. Tendo em vista que o acréscimo de -inho ou -zinho não envolve alteração da categoria lexical da base, o diminutivo possui a natureza flexional em português, levando em conta esse comportamento.

Os diminutivos ingleses distinguem-se dos diminutivos portugueses no tocante à possibilidade de mudança de classe da base. Os diminutivos deadjetivais são heterocategoriais: os adjetivos que recebem o morfema de diminutivo, para manterem a regra geral, resultam em produtos substantivos, ou seja, -ie se aproxima do âmbito derivacional.

Quanto ao princípio de organização gramatical, a natureza do diminutivo em português é ambígua. A flexão é reconhecidamente responsável pelo encerramento da palavra, ou seja, não permite que haja derivações posteriores a ela. Em português, é possível que mudanças morfofonológicas precedam os morfemas de diminutivo, mas estes se realizam anteriormente à marcação flexional de plural, isto é, não encerram palavras, revelando assim um caráter derivacional ('pãe-zinho-s'). No entanto, associando a combinação derivação- 
flexão à ordem fixa aumentativo-diminutivo que a interação entre os sufixos avaliativos portugueses exige, pode-se hipotetizar que os diminutivos estejam mais próximos ao campo flexional em comparação aos aumentativos, por exemplo.

O inglês apresenta características derivacionais em relação a esse critério. Os produtos da sufixação de -ie são, via de regra, dissílabos. Quando a base é uma forma polissílaba plural, a palavra derivada é truncada, mas permanece pluralizada. Nesses casos, o sufixo de diminutivo antecede a marcação flexional de número, ficando mais próximo ao radical ('sunn-ie-s').

Conforme já apontado na segunda seção, uma das propriedades mais típicas da morfologia avaliativa é a lexicalização. Constatou-se a ocorrência desse fenômeno com os diminutivos das duas línguas em questão. Esse comportamento confere a natureza derivacional tanto aos diminutivos portugueses como aos ingleses.

\section{Conclusão}

Este trabalho buscou investigar os mecanismos pelos quais se dá a gradação tanto na língua portuguesa como na língua inglesa. Para tal, exploraram-se, concisamente, por meio de abordagens bastante citadas na literatura, considerações relevantes acerca dos pontos de contato e de divergência entre flexão e derivação, categorias que ainda motivam debates na morfologia.

A comparação feita entre as duas línguas ao longo deste artigo mostrou que o diminutivo no inglês parece estar mais próximo ao âmbito derivacional que em português. Nesta língua, embora derivacionais, os sufixos gradativos apresentam ambiguidade em relação a alguns critérios utilizados.

Longe de exaurir o tema ou resolver a polêmica quanto às propriedades morfológicas do processo, abordou-se o fenômeno da gradação, largamente observado nas línguas do mundo com base no português e no inglês. A discussão proporcionou questionamentos acerca da natureza dos sufixos avaliativos no que diz respeito à sua opcionalidade e teor expressivo. Investigações sobre os fatores que possam favorecer o acionamento de sufixos de diminutivo e estudos mais aprofundados sobre seu comportamento como intensificador podem revelar futuras descobertas. 
Assim, contribui-se muito para as discussões do tema, encarar a problemática do fenômeno sem esquivas, para que, dialogando com as numerosas e variadas análises presentes na literatura, possam-se elucidar mais informações acerca dos diminutivos que ainda são desconhecidas.

\section{Referências}

ARMELIN, P. R. G. Sobre a interação entre as marcas de diminutivo e aumentativo no português brasileiro. ReVEL, ed. esp., n. 5, p. 1-25, 2011.

BAUER, L. Evaluative morphology: in search of universals. Studies in Language, v. 21, n. 3, p. 533-575, 1997.

BISOL, L. O diminutivo e suas demandas. DELTA, v. 26, n. 1, p. 59-85, 2010.

BUTLER, J. L. Latin-inus, -ina, -inus and-ineus: from Proto-Indo-European to the Romance languages. Berkeley: University of California, 1971.

BYBEE, Joan L. Morphology: a study of the relation between form and meaning. Amsterdam: Benjamins, 1985.

CAMARA Jr., J. M. Estrutura da Lingua Portuguesa. Petrópolis: Vozes, 1970.

CANNON, G. Historical change and English word-formation. Recent Vocabulary. New York: Lang, 1987.

ETTINGER, S. Form und Funktion in der Wortbildung. Tubingen: Narr, 1974.

FERREIRA, M. Diminutives in Brazilian Portuguese and output-output correspondence. In: GESS, R. S.; EDWARD J., R. (Ed.). Theoretical and experimental approaches to romance linguistics. New York: John Benjamin Publishing, 2005.

GONÇALVES, C. A. V. Flexão e derivação: o grau. In: VIEIRA, S. R.; BRANDÃO, S. F. Ensino de gramática: descrição e uso. São Paulo: Contexto, 2008. p. 147-168. 
GRANDI, N. Renewal and innovation in the emergence of Indo-European evaluative morphology. In: KÖRTVÉLYESSY, L.; STEKAUER, P. (Ed.). Diminutives and augmentatives in the languages of the world. Lexis: ejournal in English lexicology, v. 6, 2011.

GREENBERG, J. H. The Diachronic typological approach. In: SHIBATANI, M.; BYNON, T. (Ed.). Approaches to language typology. Oxford: Clarendon Press, 1995.

JURAFSKY, D. Universal tendencies in the Semantics of the diminutive. Language, v. 72, n. 3, p. 533-578, 1996.

KORTVÉLYESSY, L.; STEKAUER P.; VALERA, S. Word-formation in the world's languages: a typological survey. Cambridge: Cambridge University Press, 2012.

LOURES, L. H. Análise contrastiva de recursos morfológicos com função expressiva em francês e português. 2000. Tese (Doutorado em Língua Portuguesa) Universidade Federal do Rio de Janeiro, Rio de Janeiro.

NIEUWENHUIS, P. Diminutives. Unpublished PhD thesis. University of Edinburgh, 1985.

PIZA, M. T. Gênero, número e grau no continuum flexão/derivaşão em português. 2001. Dissertação (Mestrado em Língua Portuguesa) - Universidade Federal do Rio de Janeiro, Rio de Janeiro.

ROCHA, L. C. de A. Estruturas morfológicas do português. Belo Horizonte: Ed. UFMG, 1998.

ROSA, M. C. A. P. Formação de nomes aumentativos: um estudo da produtividade de alguns sufixos portugueses. 1982. Dissertação (Mestrado em Língua Portuguesa) - Universidade Federal do Rio de Janeiro, Rio de Janeiro.

SANDMANN, A. J. Morfologia lexical. São Paulo: Contexto, 1989.

SCALISE, S. Generative Morphology. Dordrecht: Foris, 1984. 
SCHNEIDER, K. P. Diminutives in English. Tübingen: Niemeyer, 2003.

STAVERMAN, W. H. Diminutivitis Neerlandica. De Gids, v. 116, p. 407-419, 1953.

STUMP, G. T. Inflection. In: SPENCER, A.; ZWICKY, A. M. (Ed.). The bandbook of Morphology. Hoboken, NJ: John Wiley \& Sons, 2001. p. 13-43.

TURNER, G. W. Stylistics. Londres: Penguin, 1973.

WIERZBICKA, A. Lexicography and conceptual analysis. Ann Arbor: Karoma, 1985.

Recebido em: 07/03/2016 Aceito: 02/05/2016 